\title{
EXPANSÃO URBANA COMO AMEAÇA À GEODIVERSIDADE: ESTUDO DE CASO EM SANTOS-SP
}

\author{
Débora Silva Queiroz $^{(a, b)}$, Maria da Glória Motta Garcia ${ }^{(b)}$
}

(a) Aluna de Pós-Graduação em Geociências. Instituto de Geociências / USP, deboraqueiroz@usp.br

(b) Núcleo de Apoio à Pesquisa em Patrimônio Geológico e Geoturismo (GeoHereditas), Instituto de Geociências / Universidade de São Paulo,mgmgarcia@usp.br

\section{Eixo: GEODIVERSIDADE, GEOARQUEOLOGIA E PATRIMÔNIO NATURAL}

\begin{abstract}
Resumo
A geodiversidade é composta pelos elementos abióticos e os processos que os originam e os modelam, possuindo valores que lhe são atribuídos de acordo com os elementos. A geodiversidade está sujeita a diversas ameaças, antrópicas ou processos naturais, necessitando de propostas de geoconservação para a proteção das características. Este artigo tem o objetivo de discutir a destruição de um potencial geossítio. Na etapa de inventário da geodiversidade de Santos (SP) foi identificado um afloramento que apresenta as evidências de movimentos tectônicos que moldaram o continente sulamericano, porém com a ampliação do Porto de Santos tal afloramento foi destruído e cedeu espaço a um pátio para contêineres e estruturas para atracar os navios. Assim, nota-se que a geodiversidade é passível de ameaças e carece de maior divulgação e pesquisas para que os locais relevantes sejam levados em consideração nos planos de gestão territorial.
\end{abstract}

Palavras chave: Geodiversidade, geoconservação, inventário, Santos.

\section{Introdução}

A geodiversidade é um termo relativamente recente, que começou a ser usado na década de 1990. Embora associado à biodiversidade, difere-se desta porque descreve a variedade do meio abiótico. Para Sharples (2002) e a Australian Heritage Commission a geodiversidade é caracterizada como "a diversidade de características, conjuntos, sistemas e processos geológicos (substrato), geomorfológicos (formas de paisagem) e do solo". Gray (2004) compreende que a geodiversidade é a variedade natural de aspectos geológicos (minerais, rochas ou fosséis), geomorfológicos e de solo, incluindo suas relações, interpretações e sistemas.

Com a expansão das pesquisas sobre geodiversidade em diversas partes do mundo, o conceito recebeu definições relatadas por vários pesquisadores. Brilha (2005) apresenta a definição da Royal Society for Nature Conservation do Reino Unido:

\footnotetext{
"A geodiversidade consiste na variedade de ambientes geológicos, fenômenos e processos ativos que dão origem a paisagens, rochas, minerais, fósseis, solos e outros depósitos superficiais que são o suporte para a vida na Terra." (BRILHA, 2005, p. 17)
}

As pesquisas brasileiras utilizam, também, a definição do Serviço Geológico do Brasil: 
O estudo da natureza abiótica constituída por uma variedade de ambientes, composição, fenômenos e processos geológicos que dão origem às paisagens, rochas, minerais, águas, fósseis, solos, clima e outros depósitos superficiais que propiciam o desenvolvimento da vida na Terra, tendo os valores intrínsecos a cultura, o estético, o econômico, o científico, o educativo e o turístico. (SILVA, 2008, p. 264).

Associados ao conceito de geodiversidade estão os geossítios, locais com ocorrência de um ou mais elementos da geodiversidade, bem delimitados geograficamente e tendo como foco o valor científico, podendo ou não ter outros valores atribuídos (Brilha, 2016). O autor denomina sítios de geodiversidade àqueles locais que possuem como foco os valores educativo e turístico, sendo que podem ou não ter outros valores atribuídos.

A geodiversidade está sujeita a diversas ameaças, seja antrópica ou por processos naturais, necessitando de conservação das características; assim, para Shaples (2002):

“(...) a geoconservação tem como objetivo a preservação da diversidade natural (ou geodiversidade) de significativos aspectos e processos geológicos (substrato), geomorfológicos (formas de paisagem) e de solo, mantendo a evolução natural (velocidade e intensidade) desses aspectos e processos." (SHARPLES, 2002, apud REVERTE, 2014, p. 30)

Brilha (2005) esclarece que é impossível conservar toda a geodiversidade. Por esta razão, tornase necessário definir locais prioritários, cujo conjunto é chamado patrimônio geológico. A definição destes locais deve seguir algumas etapas que servirão para selecionar quais elementos deverão ser conservados. Assim, tem-se o inventário, a quantificação, o enquadramento legal, a conservação, a valorização e divulgação e o monitoramento. Locais que possuam interesse científico significativo, por exemplo, devem ser protegidos para permitir o uso no futuro por estudantes e pesquisadores. A etapa de inventário da geodiversidade é imprescindível para o desenvolvimento e implantação da geoconservação, pois tais estratégias só devem ser realizadas após uma análise detalhada sobre o que é realmente representativo em cada região.

Neste sentido, vem sendo realizado, desde 2012, o inventário do patrimônio geológico do litoral paulista. Durante os trabalhos no município de Santos, percebeu-se que um afloramento interessante de rochas gnáissicas (Figura 1) havia sido comprometido com a expansão do Porto de Santos. Este artigo tem o objetivo de discutir, do ponto de vista da Geoconservação, a ameaça à geodiversidade e a destruição deste potencial geossítio, provocadas pelas obras de ampliação do referido Porto. 


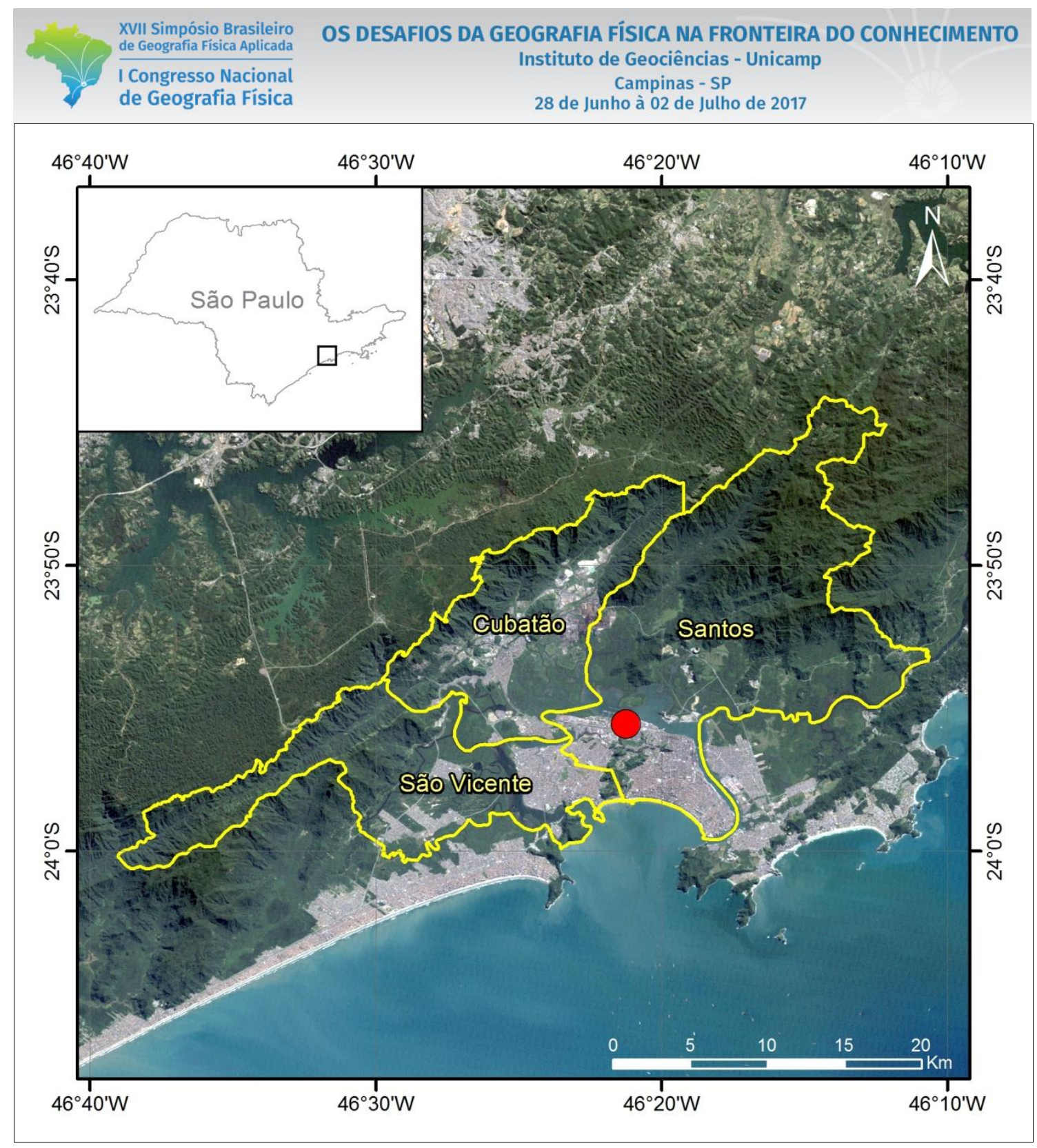

Figura 1 - Mapa de localização da área de estudo. O ponto vermelho indica o potencial geossítio destruído.

\section{Ameaça à Geodiversidade}

Dentre os elementos da geodiversidade, as rochas possuem um aspecto durável que passa a impressão de serem resistentes frente aos processos naturais que modelam a paisagem e às interferências antrópicas. Para Brilha (2005) tal ideia é correta em algumas situações, porém, em outras é revelada a fragilidade intrínseca desses elementos. A maior parte das ocorrências de degradação da geodiversidade está ligada, direta ou indiretamente, às atividades humanas e podem ocorrer em uma área de grande extensão ou em um afloramento de poucas dimensões.

Para Gray (2004 e 2013) e Brilha (2005) a maior parte das ameaças à geodiversidade estão ligadas à exploração de recursos geológicos; gestão de bacias hidrográficas; reflorestamento, 
desmatamento e atividades agrícolas desordenadas; atividades militares; atividades recreativas e turísticas sem devido planejamento; coleta de amostras de elementos da geodiversidade para fins não científicos; falta de conhecimento sobre a importância da geodiversidade; expansão urbana e instalação de obras e estruturas.

A exploração de recursos minerais, para atender a grande demanda na sociedade atual, provoca destruição da geodiversidade, seja na paisagem ou em afloramento rochosos e fossilíferos. Tal atividade também pode desmantelar os processos naturais, como é o caso da zona costeira em que a retirada de areias afeta o equilíbrio natural da dinâmica litorânea originando processos de erosão acelerada. Contudo, Brilha (2005) enfatiza que a mineração ao abrir novas lavras pode expor elementos da geodiversidade que estavam em subsuperfície.

Na gestão de bacias hidrográficas, muitas vezes, é necessário à realização de mudanças no curso d'água, bem como construção de barragens, diques e canais que causam impactos negativos na geodiversidade: alagamento de áreas com interessantes afloramentos, alteração da dinâmica dos processos naturais e modificação da paisagem local.

De acordo com Brilha (2005) o reflorestamento oculta as características geológicas de um local, o que pode causar a diminuição dos valores científicos e didáticos, em contrapartida o desmatamento pode expor elementos da geodiversidade a processos erosivos que os deteriorem. Assim, o reflorestamento, a retirada da vegetação e mesmo a agricultura devem ser feitos de modo sustentável para que possa preservar a geodiversidade da área.

As atividades militares são ameaças para a geodiversidade, pois, segundo Brilha (2005), modifica a paisagem aumentando a erosão e contaminação de solos com a utilização de maquinários e abandono de munições. Gray (2013) destaca ainda a destruição de afloramentos e produção de crateras devido aos bombardeios.

Os elementos da geodiversidade atraem a atenção das pessoas, desse modo é comum ser o destino de atividades recreativas e turísticas. Essas atividades, se realizadas de forma desordenada sem um planejamento prévio, constituem-se como uma ameaça a geodiversidade. Como exemplos pode-se citar a utilização de veículos que desmantela a dinâmica natural do local e o excesso de pessoas que pode destruir feições geomorfológicas de ambientes cársticos. Além disso, nota-se a retirada da geodiversidade para fins não acadêmicos, e que mais tarde serão descartados. Tal prática pode destruir um geossítio ou sítio de geodiversidade, pois fósseis, rochas e minerais são recursos naturais não renováveis (BRILHA, 2005).

A falta de conhecimento da população sobre a importância da geodiversidade e seus valores pode causar degradação aos elementos (Brilha, 2005 e Gray, 2013). A pichação/pintura em 
afloramentos, a retirada/quebra de estruturas são exemplos de danos a geodiversidade causados por carência em conhecimento geocientífico.

As atividades antrópicas que resultam em expansão das cidades promovem uma degradação dos elementos da geodiversidade, pois remodelam e transformam a paisagem. Morros são cortados para facilitar a construção de moradias, bem como várzeas que são aterradas e que resulta na mudança da dinâmica natural dos processos formadores da paisagem.

Atrelada à urbanização, a instalação de obras e estruturas é uma demanda cada vez maior na nossa sociedade. A construção de tais obras trazem impactos negativos sobre a geodiversidade, seja na abertura de estradas ou na construção de barragens para obtenção de energia hidrelétrica (BRILHA, 2005).

\section{Estudo de caso em Santos}

O município de Santos, inserido no litoral paulista, destaca-se tanto pelas características físicas quanto econômicas. Há rica biodiversidade oriunda da Mata Atlântica que tem a proteção assegurada principalmente nas áreas do Parque Estadual da Serra do Mar e é um importante centro econômico do Estado de São Paulo. Tal município sofre com a intensa urbanização, industrialização e turismo desenfreado que causam alterações na dinâmica dos processos naturais que ocorrem no local. Essas interferências antrópicas têm sido estudadas por vários pesquisadores, pois têm causado degradação ambiental:

\footnotetext{
"No processo de urbanização da Baixada Santista, as atividades urbanas (industriais, portuárias, comerciais ou residências) tem produzido efeitos negativos no sistema natural, descaracterizando e eliminando total ou parcialmente ecossistemas terrestres e estuarinos, e comprometendo processos naturais.” (AFONSO, 2006, p 208)
}

Em relação aos aspectos geomorfológicos o local possui duas feições que se destacam: a Serra do Mar (inserida no Orógeno Ribeira) com as vertentes escarpadas e a Planície Costeira formada por depósitos Quaternários. Quanto ao Orógeno Ribeira, a área de estudo se encontra no Terreno Embu e no Terreno Oriental (Domínio Costeiro). São compostos por rochas précambrianas que foram retrabalhadas na Orogenia Neoproterozoica Brasiliano Pan-Africana, momento em que houve a amalgamação do Paleocontinente Gondwana Ocidental (Heilbron et al, 2004). Nos limites dos terrenos são encontradas áreas de maior deformação (zonas de cisalhamento) onde ocorre lineação de estiramento e rochas miloníticas.

A Planície Costeira, por sua vez, é dividida por Suguio e Martin (1978) em Unidades e o município de Santos se insere na Unidade Itanhaém-Santos. Tal unidade é caracterizada por 
formações sedimentares depositadas no Quaternário devido às oscilações do nível médio do mar que resultou nos eventos transgressivos Cananéia (Pleistoceno) e Santos (Holoceno).

A geomorfologia local permitiu a construção de um porto que, posteriormente, se tornou um importante local de escoamento da produção brasileira, sobretudo a paulista. Desde os primórdios da colonização brasileira a área servia de embarque/desembarque de passageiros e produtos e ainda abrigo para os navios contra saqueadores. Manteve-se com o mínimo de mecanização durante três séculos e em 2 de fevereiro de 1892 (Porto de Santos, 2017) foi inaugurado o Porto de Santos.

Com o aumento das relações comerciais brasileiras, intensificaram-se cada vez mais as atividades no Porto de Santos, o que impulsionou diversas obras para a sua ampliação. Tais obras tem desmantelado a dinâmica natural da orla e destruído alguns elementos da paisagem, como é o caso do Forte de Santos (Mucivuna et al, 2016). Com os elementos da geodiversidade têm ocorrido o mesmo destino.

Durante os trabalhos de coleta de informações científicas para compor a lista de sítios potenciais do inventário do município, o trabalho de Silva et al (1977), que apresenta uma caracterização geológica de parte do litoral paulista com o objetivo de conhecer a geologia pré-cambriana da área, foi um dos utilizados. Dentre vários locais, é mostrado um afloramento composto por biotita-hornblenda-granito gnaisse cataclástico, com cristais de feldspato potássico bem estirados. Tal afloramento possui a particularidade de apresentar granada, o que aliado ao fato de estar numa mancha de biotita-granito porfiroblástico se deve a efeitos tectônicos.

Este afloramento situado na área litorânea santista tem importância para a geologia, pois apresenta as evidências de movimentos tectônicos que moldaram o continente sulamericano. Tal fato fez com que o local fosse incluído como um potencial geossítio, pois, de acordo com Brilha (2016), possui o valor científico se sobressaindo sobre outros valores. Contudo, durante a etapa de campo, realizada com o objetivo de checar as informações coletadas durante a pesquisa bibliográfica inicial, em 2016, notou-se que a área havia sofrido grandes modificações devido às obras de ampliação do Porto. 

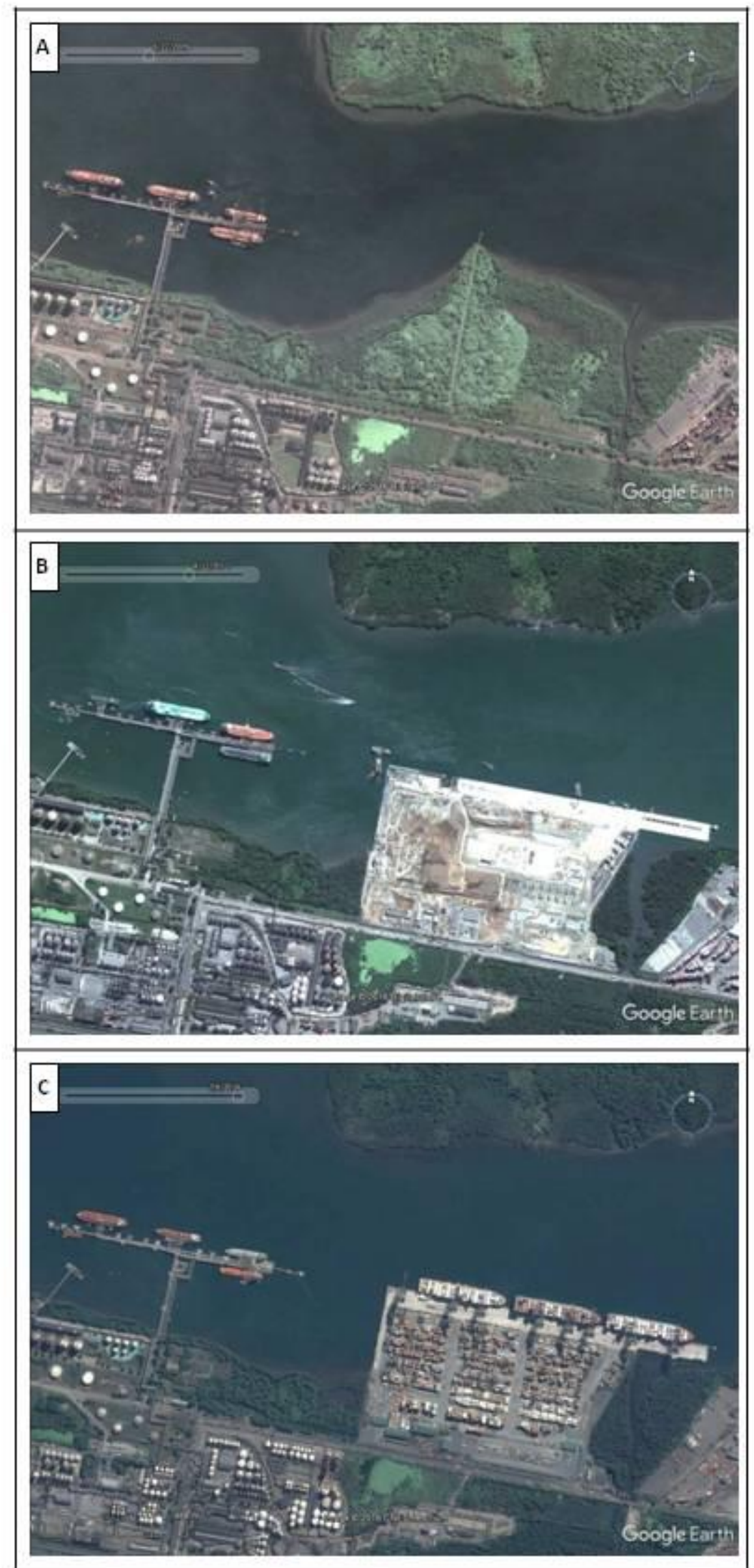

Figura 2: Área do potencial geossítio. A) Junho de 2009. B) Agosto de 2012. C) Julho de 2016. 
A Figura 2A apresenta a área junho de 2009, momento em que no local do afloramento não havia a interferência das obras de ampliação do Porto de Santos. Nota-se que apesar do entorno ser urbanizado com vias de acesso e postos industriais, é evidente a presença de uma vegetação densa, típica de mangue, com pouca interferência antrópica, o que permite o desenvolvimento dos processos naturais.

A Figura 2B mostra a área em agosto de 2012. Devido à posição estratégica, ao lado do local de abastecimento das embarcações, o afloramento e a paisagem do entorno foram alterados: ocorreram à retirada da vegetação, a destruição dos afloramentos rochosos, o soterramento do mangue, e a construção de um pátio de obras. Como resultado, ficou na paisagem um lugar modificado pelo homem com perda de elementos da geodiversidade.

A Figura 2C apresenta a área em julho de 2016 e é possível verificar a obra já concluída: onde antes havia afloramentos rochosos e vegetação típica de ambientes litorâneos, agora é um pátio destinado a abrigar contêineres, que posteriormente serão colocadas em embarcações, e uma estrutura para atracar os navios.

A Figura 3 foi tirada em trabalho de campo na área em novembro de 2016 e mostra, no primeiro plano, os contêineres que ficam depositados no local e no segundo plano os guindastes que são utilizados para transferir os contêineres do pátio para a embarcação. Assim, é possível notar que a paisagem da área estudada sofreu alterações antrópicas que destruíram a geodiversidade local.

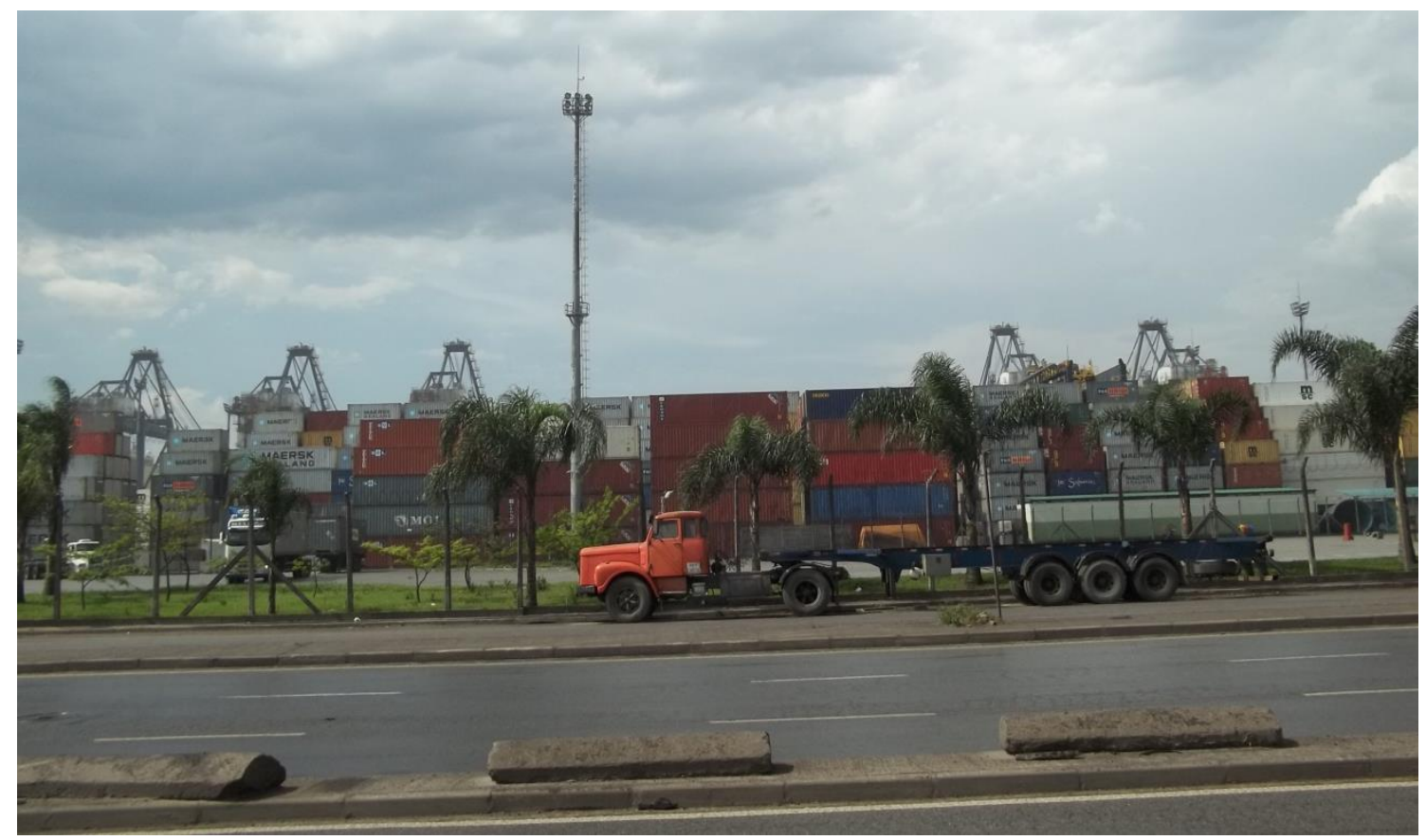

Figura 3: Vista do local do potencial geossítio transformado em um depósito de contêiner. Tirada em novembro de 2016. 


\section{Discussão e conclusões}

A geodiversidade é composta pelos elementos abióticos e os processos que os originam e os modelam, possuindo valores que lhe são atribuídos de acordo com os elementos. Tais elementos, muitas vezes, estão sob ameaças e para garantir a memória da geodiversidade deve ser realizadas propostas de geoconservação que permitirão a sua preservação.

Neste sentido, as áreas litorâneas são, em geral, muito interessantes do ponto de vista científico e didático, pois apresentam feições que exemplificam o contexto geológico e geomorfológico em que estão inseridas, além de serem atrativos turísticos. Para Brilha (2005), as obras de engenharia que são realizadas nos litorais em geral constituem sérias ameaças à geodiversidade, visto que interferem na dinâmica dos processos naturais e podem ocultar as características geológicas locais.

O município de Santos, foco deste estudo, está inserido em uma área interessante do ponto de vista geológico e geomorfológico, pois ocorrem formações rochosas do Pré-Cambriano e depósitos sedimentares do Quaternário. Assim, há elementos da geodiversidade que possuem valor científico e contam a história geológica do local, devendo ser preservados para pesquisas e conhecimento da população.

Além das características físicas, Santos se destaca no cenário brasileiro pelas características econômicas, pois é um importante centro comercial. Devido às características geológicas e geomorfológicas, desde o início da colonização brasileira, é uma cidade portuária essencial para o escoamento da produção. Desse modo, o Porto de Santos, para acompanhar o desenvolvimento da economia brasileira, passou por obras de ampliação.

Um afloramento de rochas metamórficas possui características que o particulariza e devido ao seu valor científico é um potencial geossítio devendo entrar para o inventário da geodiversidade do município de Santos com vistas a futuras ações de geoconservação. Entretanto, com a ampliação do Porto de Santos tal afloramento foi destruído para ceder lugar a local de depósito de contêineres.

Assim, nota-se que a geodiversidade, apesar do valor científico e da importância para o entendimento da evolução geológica, é passível de ameaças e carece de maior divulgação e pesquisas para que possa ser levada em consideração ao realizar uma obra de engenharia. Este fato reforça a necessidade de um inventário robusto, para que os locais relevantes do ponto de vista da geodiversidade sejam reconhecidos e incluídos em planos de gestão territorial. 


\section{Agradecimentos}

As autoras agradecem o apoio da Pró-Reitoria de Pesquisa da Universidade de São Paulo, por meio do Programa de Incentivo à Pesquisa, que permitiu a criação do Núcleo de Apoio à Pesquisa em Patrimônio Geológico e Geoturismo (GeoHereditas) e da Coordenação de Aperfeiçoamento de Pessoal de Nível Superior (Capes) pela bolsa de mestrado da primeira autora.

\section{REFERÊNCIAS}

AFONSO, C. M. A paisagem da Baixada Santista: urbanização, transformação e conservação. São Paulo, EDUSP/FAPESP. 309 p. 2006.

BRILHA, J. B. R. Patrimônio Geológico e Geoconservação: a conservação da natureza na sua vertente geológica. Braga: Palimage Editora, 190 p. 2005.

Geoheritage, 8(2): 119-134. 2016.

Inventory and Quantitative Assessment of Geosites and Geodiversity Sites: a Review.

GRAY, M. Geodiversity: Valuing and conserving abiotic nature. John Wiley e Sons Ltd., Chichester, England, p. 434. 2004.

Geodiversity: Valuing and conserving abiotic nature, 2nd edition. Londres, John Wiley \& Sons, 508 p. 2013.

HEILBRON, M., et al. Província Mantiqueira. In: MANTESSO-NETO et al. Geologia do continente Sul-americano: evolução da obra de Fernando Flávio Marques de Almeida. São Paulo. Ed. Deca. Pág. 203-236. 2004.

PORTO DE SANTOS. Resumo Histórico. Disponível em: < http://www.portodesantos.com.br/historia.php>. Acesso em: 02 fev. 2017.

MUCIVUNA et al. Aspectos geológicos, históricos e estado de conservação das fortificações da Baixada Santista, litoral paulista. In: Revista do Instituto Geológico, São Paulo, 37 (1), 29-48, 2016.

REVERTE, F. C.. Avaliação da Geodiversidade em São Sebastião - SP, como Patrimônio Geológico. 2014. Dissertação (Mestrado em Mineralogia Experimental e Aplicada) - Instituto de Geociências, Universidade de São Paulo, São Paulo, 2014.

SHARPLES, C. Concept sand Principles of Geoconservation. Disponível em Tasmanian Parks e Wildlife. Service, Australia. 2002.

SILVA, C. R. Geodiversidade do Brasil: conhecer o passado para entender o presente e prever o futuro. Rio de Janeiro, CPRM. 2008.

SILVA et al. Projeto Santos - Iguape - Relatório final geologia. Brasília, Ministério das Minas e Energia, DNPM - CPRM, v. 1. 1977.

SUGUIO, K. e MARTIN, L. Formações quaternárias marinhas do litoral paulista e sul fluminense. Quaternary marine formations of the States of São Paulo and southern Rio de Janeiro. In: International Symposium on Coastal Evolution in the Quaternary, São Paulo. Special Publication, São Paulo. n 1, 55p. 1978. 